Reestructuración industrial y empleo en Baja California, México (1989-2014)

Martín Ramírez Urquidy, Juan Antonio Meza Fregoso y Luis Armando Becerra Pérez

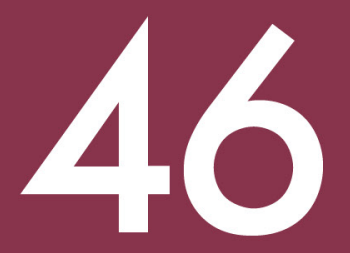

JULIO/AGOSTO 2018

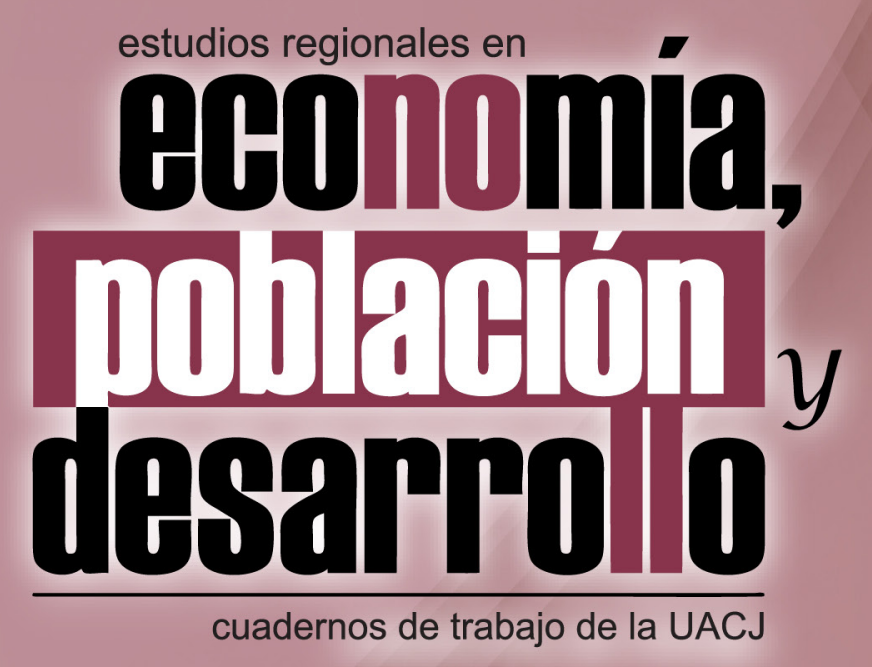




\title{
Reestructuración industrial y empleo en Baja California, México (1989-2014)
}

\author{
Martín Ramírez Urquidy, Juan Antonio Meza Fregoso \\ y Luis Armando Becerra Pérez
}

UNIVERSIDAD AUTÓNOMA DE CIUDAD JUÁREZ 


\title{
UNIVERSIDAD AUTÓNOMA DE CIUDAD JUÁREZ \\ Instituto de Ciencias Sociales y Administración
}

\author{
Cuerpo Académico de Estudios Regionales en \\ Economía, Población y Desarrollo
}

Lic. Ricardo Duarte Jáquez

Rector

M.C. David Ramírez Perea

Secretario General

Mtro. Juan Ignacio Camargo Nassar

Director del Instituto de Ciencias

Sociales y Administración

Mtro. Ramón Chavira Chavira

Director General de Difusión

Cultura y Divulgación Científica

Dr. Luis Enrique Gutiérrez Casas

Coordinador General de

Investigación y Posgrado

\section{Dr. Jaime Alberto Arellano Quiroga \\ Coordinador del Cuerpo Académico de \\ Estudios Regionales en Economía, Población y Desarrollo}

Director y editor

Dr. Luis Enrique Gutiérrez Casas

Comité editorial

Sección internacional

Dra. Sofía Boza Martínez (Universidad de Chile, Chile)

Dra. Olga Biosca Artiñano (Glasgow Caledonian

University, Reino Unido)

Dra. Ángeles Sánchez Díez (Universidad Autónoma de

Madrid, España)

Dr. Thomas Fullerton Mankin (University of Texas at

E1 Paso, Estados Unidos)

Dr. Adrián Rodríguez Miranda (Universidad de la

República, Uruguay)

Sección local

(Universidad Autónoma de Ciudad Juárez)

Dra. Myrna Limas Hernández

Dra. Ikuho Kochi

Dr. Raúl Alberto Ponce Rodríguez

Dr. Isaac Leobardo Sánchez Juárez

Dr. Héctor Alonso Barajas Bustillos

Diseño de cubierta Abigail Bautista
Estudios Regionales en Economía, Población

y Desarrollo. Cuadernos de Trabajo de la UACJ

ISSN 2007-3739

Número 46. Julio/Agosto 2018

Reestructuración industrial y empleo en

Baja California, México (1989-2014)

Martín Ramírez Urquidy, Juan Antonio Meza Fregoso

y Luis Armando Becerra Pérez

Universidad Autónoma de Ciudad Juárez

Estudios Regionales en Economía, Población y Desarrollo. Cuadernos de Trabajo de la UACJ

Año 8, No. 46 julio - agosto 2018, es una publicación bimestral editada por la Universidad Autónoma de Ciudad Juárez a través del Cuerpo Académico de Estudios Regionales en Economía, Población y Desarrollo del Instituto de Ciencias Sociales y Administración. Redacción: Avenida Universidad y H. Colegio Militar, Zona Chamizal s/n., C.P. 32300, Ciudad Juárez, Chihuahua, México. Teléfonos: (656) 688-38-00, ext. 3792. Correo electrónico: lgtz@uacj.mx.

Editor responsable: Luis Enrique Gutiérrez Casas. Reserva de derechos al uso exclusivo No. 04-2011-021713353900-102. ISSN 2007-3739, Impresa por Studio Los Dorados, calle Del Campanario, número 820-2, Santa Cecilia, C.P. 32350, Cd. Juárez, Chihuahua. Distribuidor: Subdirección de Gestión de Proyecto y Marketing Editorial. Ave. Plutarco Elías Calles 1210, Foviste Chamizal, C.P. 32310, Ciudad Juárez, Chihuahua. Este número se terminó de imprimir el 15 de junio, 2018 con un tiraje de 120 ejemplares.

Los ensayos publicados son responsabilidad exclusiva de sus autores. Se autoriza la reproducción total o parcial bajo condición de citar la fuente.

\section{Registrada en:}

Publicación afiliada a la Red Iberoamericana de Estudios del Desarrollo

Universidad Autónoma de Ciudad Juárez

Ave Plutarco Elías Calles 1210

Foviste Chamizal, C.P. 32310

Ciudad Juárez, Chihuahua, México

www.uacj.mx

(C) Universidad Autónoma de Ciudad Juárez 


\title{
Reestructuración industrial y empleo en Baja California, México (1989-2014)
}

\author{
Martín Ramírez Urquidy *, Juan Antonio Meza Fregoso ** \\ y Luis Armando Becerra Pérez ***
}

\begin{abstract}
Resumen
Este trabajo describe la evolución de la economía y de la industria manufacturera en el estado de Baja California. A partir de algunos planteamientos teóricos y empíricos desde la organización industrial $y$ del análisis de los cambios en la estructura del empleo por actividad manufacturera, el trabajo encuentra tendencias de concentración del empleo manufacturero en la gran empresa y una disminución de la participación de las pequeñas y medianas empresas, lo que puede deberse a una interacción entre el nivel tecnológico característico de las industrias que siguen favoreciendo a la gran empresa, y la reducción de la dinámica económica del estado, lo cual ha promovido la concentración industrial del empleo. Por otro lado, la participación de la microempresa dentro de la industria en el largo plazo puede deberse al deterioro de la dinámica económica con respecto a los noventa del siglo pasado, lo que motivó el emprendedurismo de personas desempleadas que abrieron microempresas para mantener su fuente de ingresos.
\end{abstract}

Palabras clave: Economía, Industria Manufacturera, tamaños de empresa, Empleo, evolución industrial.

\begin{abstract}
This paper describes the evolution of the Baja California state economy and manufacturing industry. By using some theoretical and empirical approaches from industrial organization, and by analyzing changes in the employment structure in manufacturing, the paper finds concentration trends of the manufacturing employment around large enterprises and a declining participation of small and medium enterprises, which may be due to an interaction between the technological level characterizing industries, which favors large businesses, and the diminishing economic dynamics of the state, which has promoted the industrial concentration. On the other hand, the persistence of microenterprise participation in the industry employment in the long run, may be due to deteriorating economic dynamics of the recent years as compared to the nineties of the past century, which has promoted the entrepreneurship of unemployed people who start businesses for a living.
\end{abstract}

Keywords: Economy, Manufacturing industry, Business size, Employment, Industrial evolution. JEL Classification: L25, L26.

- Recibido en: Abril de 2018.

- Aprobado en: Junio de 2018.

* Profesor-investigador de la Facultad de Economía y Relaciones Internacionales de la Universidad Autónoma de Baja California (UABC). Correo electrónico: martinramirez@uabc.edu.mx.

** Profesor de la Faculta de Contabilidad y Administración de la Universidad Autónoma de Baja California (UABC). Correo electrónico: juan.antonio.meza.fregoso@uabc.edu.mx.

*** Profesor de la Universidad Autónoma de Sinaloa (UAS). Correo electrónico: becerra@uas.uasnet.mx. 


\section{Introducción.}

La economía de Baja California (BC) ha mostrado desde hace varias décadas una dinámica particular que la ha llevado a ser una de las entidades con mayor nivel de desarrollo del país. No obstante, hay datos que sugieren que su dinámica se ha venido transformando de la mano con la economía estadounidense, que ha venido dando muestras de una desaceleración particularmente a partir de 2003, tras un período de sólido crecimiento en los noventa, que termina por manifestarse en la crisis económica que estalla en 2008. Este proceso ha implicado cambios en la estructura del empleo por sector y por estrato empresarial en Baja California, que se han materializado en una reducción del crecimiento de la manufactura que le hizo perder peso dentro de la economía.

Partiendo de este contexto, el presente trabajo describe la evolución de la economía de Baja California (BC), y busca explicar la evolución de la industria manufacturera, tendiendo como marco de referencia algunos planteamientos teóricos y empíricos desde la Organización Industrial. El trabajo presenta un análisis de los cambios en la estructura del empleo por estrato empresarial, utilizando los datos de los últimos cinco Censos Económicos elaborados por el INEGI. Se encuentra que las tendencias de concentración de la gran empresa en el empleo manufacturero de $\mathrm{BC}$ y la disminución de la participación de las pequeñas y medianas empresas, se debe a una interacción entre el nivel tecnológico característico de las industrias que se han venido instalando en la entidad, que favorece la gran empresa, y la reducción de la dinámica económica que se manifiesta en una caída de la demanda a nivel tanto binacional con California e internacional, que ha causado, por un lado, el cierre o la relocalización de pequeñas y medianas empresas promoviendo la concentración industrial; por otro lado, ha mantenido la participación de la microempresa dentro de la estructura industrial y del empleo en el largo plazo. Estos resultados pueden aportar información que nutra los esfuerzos de diseño de política pública y de desarrollo empresarial de la entidad.

\section{La evolución de la economía de Baja California 1989-2014: las bases de la reestructuración Industrial.}

El estado de Baja California es uno de los más dinámicos del país debido a su condición de frontera con Estados Unidos y sus flujos de inversión constantes. Durante gran parte del período 1995-2012, el estado ha mostrado tasas positivas de crecimiento del Producto Interno Bruto estatal estimulado en parte por el crecimiento en Estados Unidos, excepto en los años 1995, 2001, 2002, y el 2009, que se caracterizaron por procesosnacionales o internacionales de inestabilidad económica (Gráfica 1). Por ejemplo, de 1996 a 2000, el estado crece vigorosamente con tasas mayores a 7\%, incluso 10\% y $12 \%$ como las presentadas en 1997 y 2000 (Gráfica 2). Lo anterior ha propiciado que el producto 
estatal como porcentaje del PIB nacional haya crecido a lo largo de la década de los noventa según datos de INEGI. En el año de 1993 el estado contribuía con el 2.79\% del PIB nacional, mientras que para el año 2000 alcanzaba su máxima contribución con el 3.37\%.

\section{Gráfica 1}

\section{Crecimiento del Producto Interno Bruto de Estados Unidos \\ (Tasa Anual Crecimiento, \%)}

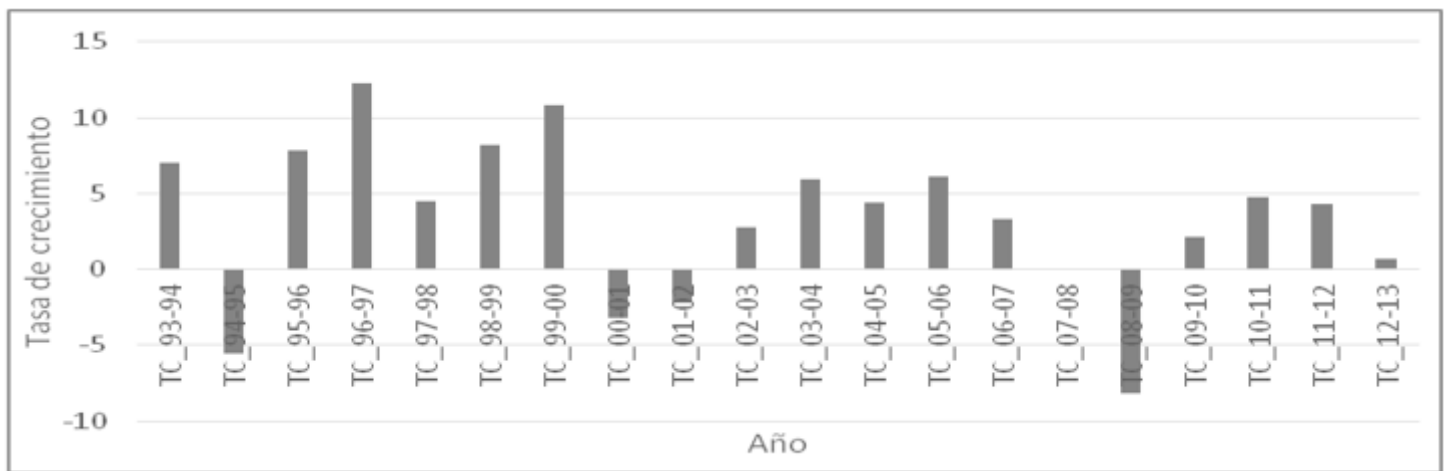

Fuente: Elaboración propia con datos de US Bureau of Economics and Statistics.

A partir de este año, la desaceleración económica en Estados Unidos impactó el crecimiento de la economía estatal al presentar una reducción de su PIB del orden 3.17\% y 2.25\% en 2001 y 2002 respectivamente, lo que hizo reducir la participación en el PIB nacional a 3.22\%. Con todo, este dato es significativamente mayor al registrado en 1993. Los años posterores a 2002 han significado un crecimiento más moderado para la región, con tasas que van de $2.5 \%$ como en 2003 , incluso hasta poco más de $6 \%$ en 2004 y 2006, lo que en el período ha promediado una tasa de $4.5 \%$, que se compara desfavorablemente con la de 8.74\% obtenida en el período 1996-2000 (Gráfica 2).

Gráfica 2

\section{Crecimiento del Producto Interno Bruto de Baja California}

(Tasa Anual Crecimiento, \%)

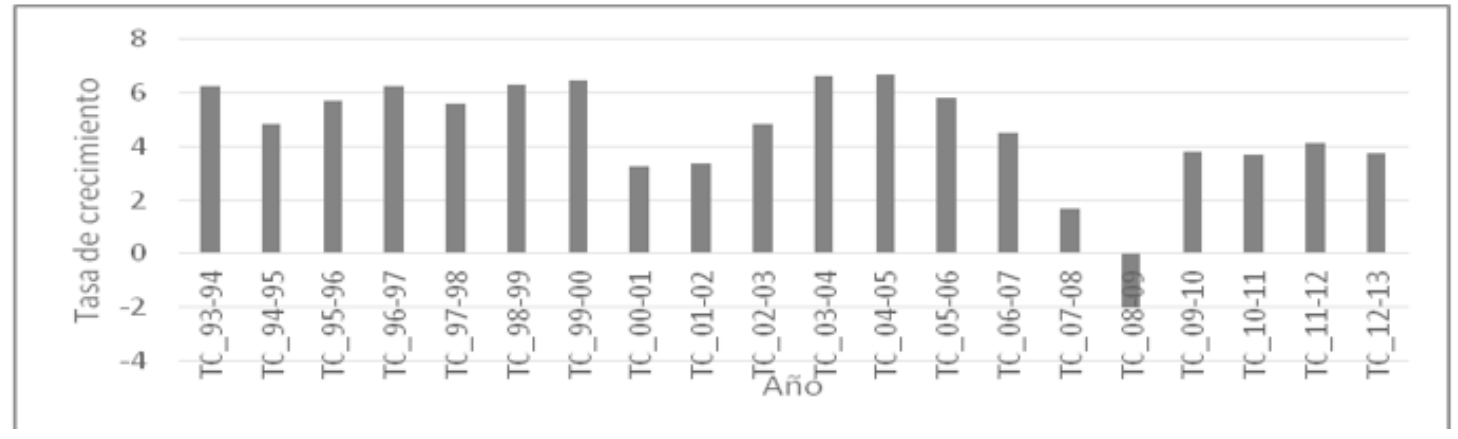

Fuente: INEGI, Banco de Información Económica. 
La IED que recibe el estado se ubica principalmente en las actividades manufactureras. Muestra de ello es que en el período 1993 a 2006 dentro de la estructura porcentual del PIB estatal, la producción manufacturera se incrementó a una tasa promedio anual del 5.4\%, y con ella su participación en el PIB, de 18\% en 1993 a 22.5\% hacia el 2000, máxima participación manufacturera en el PIB estatal (Cuadro 1). Esta dinámica fue generada por los subsectores de la manufactura que crecian a tasas cercanas o incluso mayores al 7\% en promedio anual durante el periodo en cuestión, tales como Textiles, Vestido y Cuero (7.9\%); Químicos, Derivados del Petróleo, Caucho y Plástico (7.2\%); Productos Metálicos Maquinaria y Equipo (6.1\%) y otras industrias manufactureras $(7.1 \%)$.

Con una de las mayores tasas de crecimiento en la manufactura en estos tiempos, destaca el subsector 38 de Productos Metálicos, Maquinaria y Equipo, cuyas actividades están íntimamente ligadas con la industria maquiladora de exportación y a la IED. Este subsector alcanza la mayor participación en el PIB manufacturero llegando hasta el 12.26\% en el 2000 (Cuadro 1), aunque su participación cae hasta llegar al orden del 10\% hacia el 2006. La dinámica de este subsector es la que ha determinado gran parte del comportamiento de la industria manufacturera y del PIB estatal, con la presencia de empresas de clase mundial dentro de la industria maquiladora y un crecimiento industrial fuertemente basado en la subcontratación que se origina en la complementación industrial regional en el corredor Los Ángeles - San Diego (Mungarayet al., 2014).

Cuadro 1

Estructura del Producto Interno Bruto de Baja California, 1993-2003

(Miles de pesos de 1993)

\begin{tabular}{|c|c|c|c|c|c|c|c|c|c|c|c|c|c|c|c|}
\hline & 1993 & 1994 & 1995 & 1996 & 1997 & 1998 & 1999 & 2000 & 2001 & 2002 & 2003 & 2004 & 2005 & 2006 & $\begin{array}{c}\text { Tasa de } \\
\text { Crecimiento } \\
1993-2006\end{array}$ \\
\hline TOTAL & 100 & 100 & 100 & 100 & 100 & 100 & 100 & 100 & 100 & 100 & 100 & 100 & 100 & 100 & 4.8 \\
\hline GD2 Minería & 0.2 & 0.3 & 0.3 & 0.3 & 0.2 & 0.2 & 0.2 & 0.2 & 0.2 & 0.1 & 0.1 & 0.2 & 0.2 & 0.2 & 2.6 \\
\hline GD3 Ind manufacturera & 18.0 & 18.4 & 19.2 & 20.9 & 21.2 & 22.3 & 22.3 & 22.5 & 21.4 & 19.6 & 18.8 & 19.2 & 18.9 & 19.0 & 5.4 \\
\hline A $\lim , B$ eb y Tabaco & 3.7 & 3.4 & 3.6 & 3.4 & 3.1 & 3.2 & 3.1 & 3.0 & 3.0 & 2.9 & 2.9 & 2.7 & 2.6 & 2.5 & 1.5 \\
\hline Papel, Imp y Eds & 0.5 & 0.5 & 0.5 & 0.6 & 0.6 & 0.6 & 0.6 & 0.6 & 0.7 & 0.7 & 0.7 & 0.7 & 0.7 & 0.7 & 7.0 \\
\hline Quim, Der Petr, Cau y Plas & 0.9 & 0.8 & 1.1 & 1.1 & 1.1 & 1.3 & 1.2 & 1.3 & 1.3 & 1.1 & 1.2 & 1.2 & 1.2 & 1.3 & 8.2 \\
\hline Min. no Metálicos & 1.4 & 1.6 & 1.4 & 1.6 & 1.4 & 1.2 & 1.1 & 1.1 & 1.0 & 1.1 & 1.0 & 1.0 & 1.0 & 1.0 & 2.8 \\
\hline Ind. Met Básicas & 0.1 & 0.1 & 0.1 & 0.1 & 0.1 & 0.2 & 0.2 & 0.1 & 0.1 & 0.1 & 0.2 & 0.1 & 0.1 & 0.2 & 7.6 \\
\hline Prod Met. Maq y Eq & 7.8 & 8.2 & 8.5 & 9.7 & 10.6 & 11.7 & 11.7 & 12.3 & 10.9 & 9.8 & 8.9 & 9.7 & 9.8 & 9.9 & 7.3 \\
\hline GD7 Trans, A $\mathrm{m}$ y Com & 9.0 & 9.6 & 10.1 & 10.0 & 10.5 & 10.5 & 11.0 & 11.6 & 120 & 12.3 & 12.8 & 13.7 & 14.5 & 14.7 & 8.8 \\
\hline GD8 Serv Fin, Seg, Inm & 17.5 & 17.4 & 19.2 & 17.9 & 16.2 & 17.2 & 16.9 & 15.7 & 17.1 & 17.9 & 18.8 & 18.1 & 18.3 & 18.8 & 5.3 \\
\hline GD9 Serv Com, Soc, Pers & 222 & 20.7 & 21.7 & 20.0 & 18.5 & 18.1 & 17.5 & 15.9 & 16.7 & 17.3 & 17.4 & 16.3 & 16.1 & 15.9 & 2.0 \\
\hline
\end{tabular}

Fuente: Elaboración propia, Banco de Información Económica, cuentas nacionales (INEGI). 
Tras la desaceleración de la economía estadunidense, reestructuraciones industriales y el ascenso de otras sectores, la participación del sector manufacturero cae al orden del 19\% en los años subsecuentes hasta el 2013, con una tasa crecimiento promedio anual 1.30\% (Cuadro 2), cuando la economía crecía en el orden de $2.52 \%$. A diferencia del periodo anterior, los subsectores que más crecieron fueron la Fabricación de insumos, productos textiles y acabado de textiles $(7.86 \%)$, Industria del papel (6.85\%), la Fabricación de derivados del petróleo y carbón; Industria química; Industria del plástico y del hule (5.34\%), Industria de Bebidas y tabaco (4.26) y la alimentaria (3.13\%). Los subsectores que han mostrado un reducido desempeño son la industria de madera (-7.19\%), Fabricación de prendas de vestir y cuero (-2.31\%), Industrias de madera (-7.19\%) e Industrias Metálicas Básicas (-2.32\%), y muebles, colchones y persianas (-1\%).

Salvo las industrias químicas y derivados del petróleo, es claro que los sectores que tradicionalmente imprimían el dinamismo industrial y económico de Baja California, han reducido su importancia y han mostrado un crecimiento en el mejor de los casos cercano al promedio estatal durante la última década, como lo son Otras industrias manufactureras que muestran un crecimiento de 2.6\%; y las Industrias de Fabricación de maquinaria y equipo, y Fabricación de equipo de computación y comunicación $(0.81 \%)$, cuyo impacto sobre el total de la industria es sustantivo por su importante participación dentro del PIB aunque declinante (ver cuadro 2 ). 


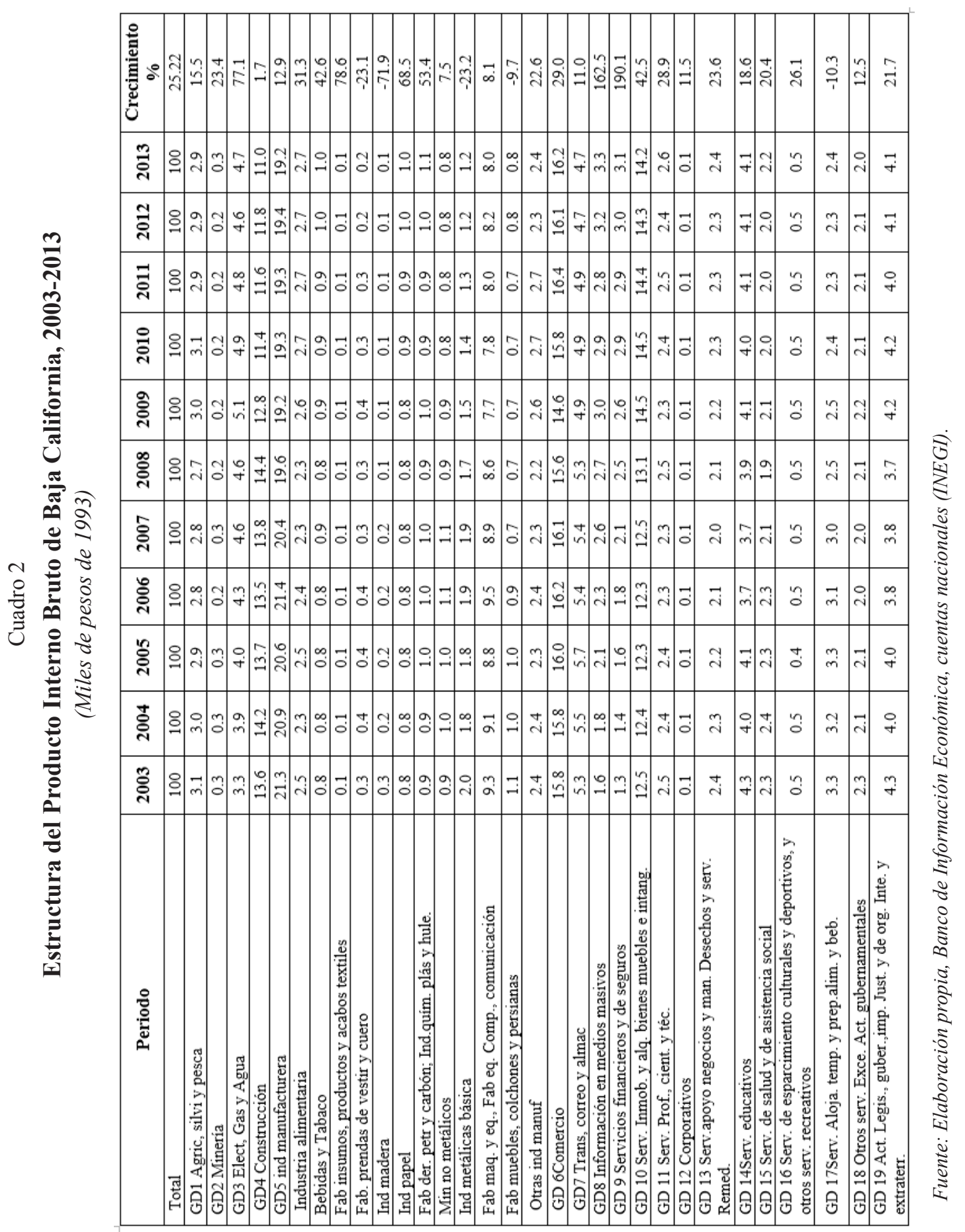


Con respecto a la estructura industrial por tamaños de empresa y su contribución en el empleo para el sector industrial durante los 20 años de análisis, se encuentran algunos patrones de largo plazo en la industria manufacturera de Baja California. Por un lado, existe una tendencia a la concentración del empleo en la gran empresa como se observa en el cuadro 3, cifra que pasa de $46 \%$ en 1989 a más de $75 \%$ en 2009 . Por otro lado, se observa un deterioro importante en la participación de las pequeñas y medianas empresas dentro del empleo manufacturero, que en el caso de las pequeñas empresas va de presentar $13.8 \%$ en 1989 a solo $4.1 \%$ en el 2009 , una caída de casi 10 puntos porcentuales (Cuadro 3).

Las medianas empresas sufren una caída en su participación incluso mayor que las pequeñas, de $34.0 \%$ en 1989 a $14.9 \%$ en el 2009, una caída de cerca de 20 puntos porcentuales, aunque en 2014 se recupera levemente. El estrato microempresarial mantiene una peso estable desde 1989, y no se percibe un patrón declinante en el período de análisis, más bien se mantiene entre $5 \%$ y $6 \%$, lo que demuestra que las transformaciones del sector manufacturero no han modificado su dinámica económica.

Cuadro 3

\section{Empleo manufacturero por estrato empresarial en Baja California (Participación \% por estrato)}

\begin{tabular}{|l|c|c|c|c|c|c|}
\hline \multirow{2}{*}{} & \multicolumn{7}{|c|}{ Año } \\
\cline { 2 - 7 } & 1989 & 1994 & 1999 & 2004 & 2009 & 2014 \\
\hline Micro & $5.60 \%$ & $6.90 \%$ & $4.90 \%$ & $4.60 \%$ & $5.80 \%$ & $5.32 \%$ \\
\hline Pequeña & $13.80 \%$ & $10.30 \%$ & $5.90 \%$ & $5.10 \%$ & $4.10 \%$ & $4.89 \%$ \\
\hline Mediana & $34.00 \%$ & $29.20 \%$ & $24.30 \%$ & $19.40 \%$ & $14.90 \%$ & $16.42 \%$ \\
\hline Grande & $46.60 \%$ & $53.60 \%$ & $64.90 \%$ & $71.00 \%$ & $75.20 \%$ & $73.37 \%$ \\
\hline
\end{tabular}

Fuente: Elaboración propia con datos de los Censos Económicos (INEGI). 


\section{$\rightarrow$ 3. Análisis de la evolución de las industrias y el empleo por tamaños de empresa en el periodo 1989-2015.}

Para explicar la evolución de la industria manufacturera y tamaños de empresa en BC por subsectores de actividad, se realiza un análisis de los cambios en la estructura del empleo, utilizando información de los últimos cinco Censos Económicos elaborados por el INEGI, con la particularidad de que la base de datos fue dividida en dos periodos: 1989-1999 y 2004-2014. Esta agrupación de la información responde al hecho de que el INEGI elaboró las bases de datos con metodologías diferentes. En los primeros tres Censos (1989, 1994 y 1999), se utilizó la Clasificación Mexicana de Actividades y Productos (CEMAP 1994), mientras en los últimos tres (2004, 2009 y 2014) se utilizó el Sistema de Clasificación Industrial de América del Norte (SCIAN, México 2002). En el clasificador SCIAN, aparte de existir nuevas clases de actividad que no estaban en el clasificador CMAP, se reubicaron algunas clases dividiéndolas en varias clases de actividad del nuevo clasificador (SCIAN). Ello trae inconsistencias al tratarlas de fusionarlas, por lo que sería metodológicamente incorrecto hacer una homologación entre los dos tipos de censos ya que irremediablemente se perdería continuidad de la información, (INEGI, 2010: P.5). Para estratificar las empresas manufactureras por tamaño se utiliza el criterio de la Secretaria de Economía, mismo que está publicado en el Diario Oficial de la Federación de fecha 30 de junio de 2009, que clasifica a las microempresas como aquellos establecimientos que tienen de 1 a 10 empleados, las pequeñas de 11 a 50, las medianas de 51 a 250 , y las grandes de 251 en adelante.

\subsection{Análisis de los años noventa.}

Los datos de la sección anterior indican una pérdida de participación en el empleo de las Micro, Pequeñas y Medianas Empresas (MiPyMEs) del sector industrial de Baja California en la década de los 90, mientras que el empleo en la gran empresa muestra un salto muy importante dentro de la estructura del empleo. Estos datos se presentan en el marco de una economía estadounidense que estaba en fase expansiva con sus repercusiones favorables sobre el crecimiento de la economía de Baja California a través de la manufactura, y muy particularmente, de subsectores con alta participación y crecimiento como el de Productos Metálicos, Maquinaria y Equipo, y el de Otras Industrias Manufactureras, que ampliaron su participación en la década llegando a represen$\operatorname{tar} 68 \%$ de la industria y cerca de $16 \%$ en la economía. Son estos subsectores donde se concentra la industria maquiladora de exportación y la mayor parte de la IED que llega a Baja California. Otros grupos de actividades que tuvieron una importante dinámica, aunque con menor peso en la manufactura, fueron los Textiles, Vestido y Cuero; Químicos, Derivados del Petróleo, Caucho y Plástico; y las Industrias Metálicas Básicas. 
A nivel desagregado, la gran empresa aumentó su participación en prácticamente todos los subsectores, con excepción de Productos Minerales No Metálicos (Excluye los derivados del petróleo y del carbón). En el subsector Textiles, Prendas de Vestir e Industria del Cuero, prácticamente dobló su participación. Otros sectores donde aumenta su participación son Sustancias Químicas, Productos Derivados del Petróleo y del Carbón de Hule y de Plástico; y en el subsector de Productos Metálicos, Maquinaria y Equipo, que incluye instrumentos quirúrgicos y de precisión; todos sectores que mostraron una importante dinámica durante la década y registran una importante participación en la industria.

Las áreas donde las microempresas registran una mayor participación en el empleo (1999), son las Industrias Metálicas Básicas con 29.3\%; los Productos Alimenticios, Bebidas y Tabaco con 24\%; y subsector Productos Minerales no Metálicos (excluye los derivados del petróleo y del carbón) con 18.2\%, y Productos de Papel, Imprentas y Editoriales con 17\%. Si bien algunos de estos sectores crecen vigorosamente durante la década, sus pesos relativos en la industria y en la economía se mantuvieron bajos; no obstante, son los que agrupan las ramas productivas tradicionales que requieren bajos montos de capital, bajo nivel de tecnología, registran menores barreras a la entrada, y bien podrían estar más vinculados con los emprendedores locales. Solo en los subsectores Productos Alimenticios, Bebidas y Tabaco y en Industrias Metálicas Básicas, se percibe una clara ampliación de la participación de la microempresa, pero de igual forma son subsectores de baja participación e incluso declinante como en el caso de los Alimentos. Los subsectores en los que menos participa las microempresas son Sustancias Químicas, Productos derivados del Petróleo y Hule y de Plástico, con 1.3\%; y el de Productos Metálicos, Maquinaria y Equipo, que incluye instrumentos quirúrgicos y de precisión con 1.9\%. La baja participación de la microempresa puede explicarse por la naturaleza de las industrias en cuestión, ya que tienen un grado mayor de complejidad, magnitud de capital requerido y grado tecnológico, que impide a las microempresas participar más vigorosamente (Cuadro 4).

El peso del estrato de pequeñas empresas en la manufactura se reduce sustancialmente prácticamente en todos los subsectores, con excepción de la Industrias Metálicas Básicas, donde de hecho existe una importante transformación al representar 70\% del empleo y desplazar a los estratos superiores. Sin embargo, ello no contrarresta la importante pérdida de participación del estrato ya que este sector es de baja participación en la manufactura y en la economía en general, aunque con un importante vínculo con los emprendedores locales.

Los subsectores donde se percibe más la caída del peso de la pequeña empresa es el de Textiles, Prendas de Vestir e Industria del Cuero, donde va de $26.7 \%$ a $9.8 \%$ a pesar de que el sector ha creció de manera importante durante la década y ampliado su participación en la manufactura. Otras pérdidas importantes del estrato se dan en el subsector de Sustancias Químicas, Productos 
Derivados del Petróleo y del Carbón, Hule y de Plástico, que va de $24.9 \%$ a $7.10 \%$ y en Otras Industrias Manufactureras, donde se registra una caída de $22.3 \%$ a 3.6\%. Es importante destacar que estas industrias muestran un crecimiento importante durante la década que les ha permitido ampliar su participación en la economía, aunque ello no ha sido favorable para el estrato de pequeñas empresas.

Cuadro 4

Participación en el empleo por estrato empresarial y subsector de la manufactura de Baja California

$$
1989-1999(\%)
$$

\begin{tabular}{|c|c|c|c|c|c|}
\hline \multirow{2}{*}{ Subsector industria } & \multirow{2}{*}{ Año } & \multicolumn{4}{|c|}{ Tamaño de empresa } \\
\hline & & Micro & Pequeña & Mediana & Grande \\
\hline \multirow{3}{*}{31 Productos alimenticios, bebidas y tabaco. } & 1989 & $14.50 \%$ & $18.30 \%$ & $38.90 \%$ & $28.30 \%$ \\
\hline & 1994 & $22.10 \%$ & $14.10 \%$ & $28.70 \%$ & $35.10 \%$ \\
\hline & 1999 & $24.00 \%$ & $12.20 \%$ & $30.00 \%$ & $33.80 \%$ \\
\hline \multirow{3}{*}{$\begin{array}{l}32 \text { Textiles, prendas de vestir e industria del } \\
\text { cuero. }\end{array}$} & 1989 & $4.60 \%$ & $26.70 \%$ & $47.50 \%$ & $21.20 \%$ \\
\hline & 1994 & $6.90 \%$ & $19.40 \%$ & $50.00 \%$ & $23.70 \%$ \\
\hline & 1999 & $3.30 \%$ & $9.80 \%$ & $45.00 \%$ & $41.90 \%$ \\
\hline \multirow{3}{*}{$\begin{array}{l}33 \text { Industrias de la madera y productos de } \\
\text { madera. Incluye muebles. }\end{array}$} & 1989 & $4.90 \%$ & $16.80 \%$ & $32.50 \%$ & $45.70 \%$ \\
\hline & 1994 & $7.80 \%$ & $17.10 \%$ & $47.10 \%$ & $28.10 \%$ \\
\hline & 1999 & $5.40 \%$ & $9.80 \%$ & $28.60 \%$ & $56.20 \%$ \\
\hline \multirow{3}{*}{$\begin{array}{l}34 \text { Papel y productos de papel, imprentas y } \\
\text { editoriales. }\end{array}$} & 1989 & $13.50 \%$ & $17.00 \%$ & $44.60 \%$ & $24.90 \%$ \\
\hline & 1994 & $25.30 \%$ & $18.90 \%$ & $9.30 \%$ & $46.50 \%$ \\
\hline & 1999 & $16.80 \%$ & $8.60 \%$ & $30.50 \%$ & $44.00 \%$ \\
\hline \multirow{3}{*}{$\begin{array}{l}35 \text { Sustancias químicas, productos derivados } \\
\text { del petróleo y del carbón de hule y de plástico. }\end{array}$} & 1989 & $2.20 \%$ & $24.90 \%$ & $18.10 \%$ & $54.80 \%$ \\
\hline & 1994 & $1.70 \%$ & $10.70 \%$ & $35.20 \%$ & $52.50 \%$ \\
\hline & 1999 & $1.30 \%$ & $7.10 \%$ & $33.20 \%$ & $58.40 \%$ \\
\hline \multirow{3}{*}{$\begin{array}{l}36 \text { Productos minerales no metálicos. Excluye } \\
\text { los derivados del petróleo y del carbón. }\end{array}$} & 1989 & $21.30 \%$ & $20.10 \%$ & $11.70 \%$ & $46.90 \%$ \\
\hline & 1994 & $18.30 \%$ & $19.90 \%$ & $26.60 \%$ & $35.30 \%$ \\
\hline & 1999 & $18.20 \%$ & $14.30 \%$ & $34.70 \%$ & $32.70 \%$ \\
\hline \multirow{3}{*}{37 Industrias metálicas básicas. } & 1989 & $7.20 \%$ & $0.00 \%$ & $92.80 \%$ & $0.00 \%$ \\
\hline & 1994 & $29.30 \%$ & $70.70 \%$ & $0.00 \%$ & $0.00 \%$ \\
\hline & 1999 & $29.30 \%$ & $70.70 \%$ & $0.00 \%$ & $0.00 \%$ \\
\hline \multirow{3}{*}{$\begin{array}{l}38 \text { Productos metálicos, maquinaria y equipo. } \\
\text { Incluye instrumentos quirúrgicos y de } \\
\text { precisión. }\end{array}$} & 1989 & $1.80 \%$ & $7.30 \%$ & $27.60 \%$ & $63.20 \%$ \\
\hline & 1994 & $2.30 \%$ & $5.90 \%$ & $21.30 \%$ & $70.50 \%$ \\
\hline & 1999 & $1.90 \%$ & $3.20 \%$ & $17.60 \%$ & $77.40 \%$ \\
\hline \multirow{3}{*}{39 Otras industrias manufactureras. } & 1989 & $7.90 \%$ & $22.30 \%$ & $69.70 \%$ & $0.00 \%$ \\
\hline & 1994 & $1.20 \%$ & $3.60 \%$ & $17.10 \%$ & $78.20 \%$ \\
\hline & 1999 & $1.20 \%$ & $3.60 \%$ & $17.10 \%$ & $78.20 \%$ \\
\hline Total sector industrial & 1989 & $5.60 \%$ & $13.80 \%$ & $34.00 \%$ & $46.60 \%$ \\
\hline Total sector industrial & 1994 & $6.90 \%$ & $10.30 \%$ & $29.20 \%$ & $53.60 \%$ \\
\hline Total sector industrial & 1999 & $4.90 \%$ & $5.90 \%$ & $24.30 \%$ & $64.90 \%$ \\
\hline
\end{tabular}

Fuente: Elaboración propia con datos de los Censos Económicos (INEGI). 


\subsection{Análisis del periodo 2000-2014.}

Los datos para el periodo 2000-2009, confirman la tendencia de la década anterior: una concentración del empleo en la gran empresa, la estabilidad de la participación de la microempresa, y la profundización de la caída de la pequeña y mediana empresa dentro de la estructura del empleo en el sector (Cuadro 5). Ello sucede en entorno económico menos favorable que la década anterior que se perfilaba a la crisis que estallarían en 2008 con una desaceleración de EEUU y sus consecuentes efectos en el PIB estatal.

A nivel de la industria manufacturera y sus subsectores, existe un deterioro importante con respecto a la década anterior. La industria manufacturera en su conjunto pasa de representar $22.5 \%$ de la economía en 2000 a 19.6\% para el 2013. Casi todos los subsectores reducen su partición dentro de la economía, particularmente aquellos considerados otrora más dinámicos como Productos Metálicos, Maquinaria y Equipo, que cae de $12.3 \%$ a 9.9\%; Alimentos, Bebidas y Tabaco que pasa de $3.7 \%$ a $2.5 \%$; Madera y sus productos de $1 \%$ a $0.6 \%$, por decir los más importantes. Solo dos subsectores incrementaron su peso en la economía como la de Papel, Imprenta y Editoriales y Otras Industrias Manufactureras.

Al interior del sector industrial de Baja California, las microempresas están concentradas en ramas y actividades productivas tradicionales y de bajo nivel tecnológico, para las cuales pueden tener ventajas relativas con respecto a otros tipos de empresa. En otros casos, la participación del estrato obedece a otros factores derivados de las escasas oportunidades laborales y bajo crecimiento. De acuerdo al cuadro 5, la microempresa participa sustancialmente en el empleo en los subsectores de la Industria alimentaria, subiendo de $36.8 \%$ en 2004 a $42.7 \%$ en 2009, para nuevamente reducirse a 34.04\%en 2014; en la Industria de las bebidas y del tabaco con participación creciente con $13.5 \%$ en 2004 , a $22.8 \%$ y $33.02 \%$ en 2009 y 2014 respectivamente; así como en la industria de la madera, cuya participación se han incrementado sustancialmente de $14.10 \%$ en 2004, a 18.2 en 2009 y $22.8 \%$ en 2014. Otro subsector en el que la microempresa tiene aún una amplia pero declinante presencia es la Impresión e industrias conexas, donde al último censo reportó $15.55 \%$ de participación, cuando en el 2004 y 2009 alcanzaba una participación de 24\% y 28\%respectivamente. Otros subsectores donde la microempresa cuenta con una participación moderada son la Fabricación de productos textiles, excepto prendas de vestir, en donde ha ampliado presencia; fabricación de productos a base de minerales no metálicos; Fabricación de productos metálicos y la Fabricación de equipo de transporte, que alcanzan entre 12\% y 5\% de participación. Es interesante destacar que existen diferencias sustanciales en la dinámica de los micronegocios entre un periodo y otro, ya que de 2004 a 2009 este estrato amplia participación en 12 de 21 subsectores, mientras que de 2009 al 2014, gana terreno en solo 4, lo que podría estar vinculado con diferenciales en el ambiente económico. 
Las pequeñas empresas han venido teniendo un deterioro en su aportación al empleo de $13.8 \%$ en 1989 hasta $4.10 \%$ 2009, aunque ya en el último censo se advierte una leve mejoría en su participación al llegar a 4.89\%. De las 21 actividades analizadas, entre de 2004 y 2009 las empresas pequeñas ganaron terreno solo en 3 y cayeron en 17, mientras que entre 2009 y 2014 se invierte la situación, ampliando su participación en 13 y disminuyéndola en 7.

En el último censo con datos del 2014, las pequeñas empresas aportaron sustancialmente en el Curtido y acabado de cuero y piel, y fabricación de productos de cuero, piel y materiales sucedáneos (29.5\%), donde además se observa un agudo incremento en participación de niveles de 7\% en los Censos 2004 y 2009desplazando a las microempresas. De la misma forma, aportaron de manera creciente en la Industria de la madera (19.65\%), sobresaliendo sobre las grandes empresas; en la Fabricación de productos a base de minerales no metálicos (14.2\%); en la Industria alimentaria (13.71\%), aunque ha venido perdiendo terreno contra la aportación de las grandes y las medianas empresas; Industria de las bebidas y del tabaco (13.05\%); Fabricación de productos textiles, excepto prendas de vestir (12.75\%), donde tras haber bajado su participación entre 2004 y 2009, ahora la eleva; y Fabricación de prendas de vestir (5.29\%) en el que también existieron avances.

Uno de las pérdidas de participación en el empleo más importantes en la industria es el de las medianas empresas. Si bien existen algunos subsectores en el que su aportación es sustancial, versus los otros estratos, su participación ha caído sistemáticamente desde 1989 hasta 2009, en el que pasa de $34 \%$ a 14.90\%, y se recupera solo al 2014 con una aportación de 16.42\%. En 2009, los subsectores donde el empleo de las medianas empresas se concentraba son la Fabricación de Insumos Textiles y Acabados de Textiles, con una participación de 92\%; la Industria Química con una participación de 41\%; y en la Fabricación de Prendas de Vestir, con una participación de 42\%. La mediana empresa pierde participación en el empleo en la manufactura en su conjunto, y en 14 de los 21 subsectores considerados, principalmente la Industria de las bebidas y del tabaco; Fabricación de productos textiles, excepto prendas de vestir; Curtido y acabado de cuero y piel, y fabricación de productos de cuero, piel y materiales sucedáneos; Fabricación de productos derivados del petróleo y del carbón; Industrias metálicas básicas; Fabricación de productos metálicos; Fabricación de muebles, colchones y persianas, subsectores donde la participación de la gran empresa ha venido fortaleciéndose. Hacia el 2014, Fabricación de productos textiles, excepto prendas de vestir alcanzó 50.16\%, cuando cinco años atrás no representaba ningún peso en la industria; la Industria de la madera con $43.70 \%$, Fabricación de insumos textiles y acabado de textiles, que cae de $42 \%$ a $34 \%$; Industria del papel, que ha venido desempeñándose favorablemente para el estrato y alcanza 26\%; y en la Industria del plástico y del hule, aunque con una participación levemente decreciente de $31.90 \%$ en 2014 a $25 \%$ en 2014 . Otras industrias en que la mediana empresa contribuye medianamente en 2014 son las Industrias metálicas básicas; Impresión e industrias conexas; Curtido 
y acabado de cuero y piel, y fabricación de productos de cuero, piel y materiales sucedáneos; Fabricación de productos a base de minerales no metálicos; Industria alimentaria, Fabricación de equipo de transporte; Industria de las bebidas y del tabaco y la Fabricación de productos metálicos. Mientras que en el periodo 2005-2009, 6 de los 21 subsectores vieron mejorar la participación de las pequeñas empresas en el empleo, hacia el 2014 este número sube a 12, lo cual muestra que el desempeño reciente del estrato ha sido más favorable que en otros periodos.

Por su parte, en lo que respecta a las grandes empresas, se ha visto un dramático incremento de su participación en el empleo en el largo plazo. De hecho, es el único estrato que consistentemente ha elevado su importancia en la manufactura. Los datos señalan que mientras en 1989, la gran empresa aportaba 46\% del empleo manufacturero, hacia el 2009 llega a más del 75\%. En 2004 se observa una leve disminución de su participación ante el ligero ascenso de la participación de las pequeñas y medianas empresas.

La gran empresas es particularmente importante en la Fabricación de productos derivados del petróleo y del carbón, donde al 2014 aporta el 99.75\% del personal ocupado; la Fabricación de equipo de transporte (88.14\%), Fabricación de equipo de computación, comunicación, medición y de otros equipos, componentes y accesorios electrónicos (87.81\%); Otras industrias manufactureras (86.32\%); Fabricación de accesorios, aparatos eléctricos y equipo de generación de energía eléctrica (79.68\%); Fabricación de maquinaria y equipo (79.45\%); Industria química (75.97\%); Fabricación de productos metálicos (68.55\%); Industria del plástico y del hule (67.84\%); Industria del papel (66.42\%); y Fabricación de equipo de transporte (65.82\%), por decir los más importantes. Todas estas industrias se caracterizan por requerir escalas de producción amplias, mayor grado de sofisticación, y cuantiosas inversiones en capital. Estos sectores pueden ser típicamente de exportación con la participación de la IED. En 2009, el estrato de las grandes empresas incremento su participación en 15 de los 21 subsectores analizados, y 6 se mantuvo, mientras que, en 2014, la gran empresa mejora en 10 subsectores y 11 permanecen sin cambios. 
Cuadro 5

Participación de las MiPyMEs de Baja California en el empleo industrial por subsector $2000-2014(\%)$

\begin{tabular}{|c|c|c|c|c|c|}
\hline \multirow[t]{2}{*}{ Subsector industria } & \multirow[t]{2}{*}{ Año } & \multicolumn{4}{|c|}{ Tamaño de empresa } \\
\hline & & Micro & Pequeña & Mediana & Grande \\
\hline \multirow{3}{*}{311 Industria alimentaria. } & 2004 & $36.80 \%$ & $16.80 \%$ & $18.30 \%$ & $28.20 \%$ \\
\hline & 2009 & $42.70 \%$ & $15.70 \%$ & $18.20 \%$ & $23.30 \%$ \\
\hline & 2014 & $34.04 \%$ & $13.71 \%$ & $19.16 \%$ & $33.08 \%$ \\
\hline \multirow{3}{*}{$\begin{array}{l}312 \text { Industria de las bebidas y del } \\
\text { tabaco. }\end{array}$} & 2004 & $13.50 \%$ & $14.50 \%$ & $28.10 \%$ & $43.90 \%$ \\
\hline & 2009 & $22.80 \%$ & $12.90 \%$ & $15.10 \%$ & $49.20 \%$ \\
\hline & 2014 & $33.02 \%$ & $13.05 \%$ & $18.13 \%$ & $35.81 \%$ \\
\hline \multirow{3}{*}{$\begin{array}{l}313 \text { Fabricación de insumos textiles } \\
\text { y acabado de textiles. }\end{array}$} & 2004 & $1.50 \%$ & $14.70 \%$ & $83.80 \%$ & $0.00 \%$ \\
\hline & 2009 & $2.10 \%$ & $6.40 \%$ & $91.50 \%$ & $0.00 \%$ \\
\hline & 2014 & $1.50 \%$ & $6.60 \%$ & $35.53 \%$ & $56.38 \%$ \\
\hline \multirow{3}{*}{$\begin{array}{l}314 \text { Fabricación de productos } \\
\text { textiles, excepto prendas de vestir. }\end{array}$} & 2004 & $9.90 \%$ & $17.60 \%$ & $72.50 \%$ & $0.00 \%$ \\
\hline & 2009 & $10.40 \%$ & $9.60 \%$ & $0.00 \%$ & $79.90 \%$ \\
\hline & 2014 & $12.01 \%$ & $12.75 \%$ & $50.16 \%$ & $25.08 \%$ \\
\hline \multirow{3}{*}{$\begin{array}{l}315 \text { Fabricación de prendas de } \\
\text { vestir. }\end{array}$} & 2004 & $4.40 \%$ & $7.00 \%$ & $46.70 \%$ & $41.80 \%$ \\
\hline & 2009 & $6.50 \%$ & $9.00 \%$ & $42.10 \%$ & $42.50 \%$ \\
\hline & 2014 & $5.29 \%$ & $11.46 \%$ & $34.63 \%$ & $48.61 \%$ \\
\hline \multirow{3}{*}{$\begin{array}{l}316 \text { Curtido y acabado de cuero y } \\
\text { piel, y fabricación de productos de } \\
\text { cuero, piel y materiales sucedáneos. }\end{array}$} & 2004 & $30.80 \%$ & $7.50 \%$ & $61.70 \%$ & $0.00 \%$ \\
\hline & 2009 & $4.30 \%$ & $6.70 \%$ & $29.40 \%$ & $59.70 \%$ \\
\hline & 2014 & $5.09 \%$ & $29.48 \%$ & $22.38 \%$ & $43.06 \%$ \\
\hline \multirow{3}{*}{321 Industria de la madera. } & 2004 & $14.10 \%$ & $16.10 \%$ & $36.30 \%$ & $33.50 \%$ \\
\hline & 2009 & $18.20 \%$ & $8.70 \%$ & $43.70 \%$ & $29.30 \%$ \\
\hline & 2014 & $22.82 \%$ & $19.65 \%$ & $46.27 \%$ & $11.26 \%$ \\
\hline \multirow{3}{*}{322 Industria del papel. } & 2004 & $2.10 \%$ & $3.20 \%$ & $20.30 \%$ & $74.40 \%$ \\
\hline & 2009 & $3.00 \%$ & $4.80 \%$ & $28.60 \%$ & $63.60 \%$ \\
\hline & 2014 & $3.38 \%$ & $4.14 \%$ & $26.06 \%$ & $66.42 \%$ \\
\hline \multirow{3}{*}{323 Impresión e industrias conexas. } & 2004 & $28.40 \%$ & $16.10 \%$ & $0.00 \%$ & $55.50 \%$ \\
\hline & 2009 & $24.60 \%$ & $9.70 \%$ & $18.60 \%$ & $47.10 \%$ \\
\hline & 2014 & $15.55 \%$ & $7.53 \%$ & $22.49 \%$ & $54.44 \%$ \\
\hline \multirow{3}{*}{$\begin{array}{l}324 \text { Fabricación de productos } \\
\text { derivados del petróleo y del carbón. }\end{array}$} & 2004 & $1.00 \%$ & $3.80 \%$ & $39.40 \%$ & $55.80 \%$ \\
\hline & 2009 & $3.50 \%$ & $2.90 \%$ & $0.00 \%$ & $93.60 \%$ \\
\hline & 2014 & $0.25 \%$ & $0.00 \%$ & $0.00 \%$ & $99.75 \%$ \\
\hline \multirow{3}{*}{325 Industria química. } & 2004 & $8.00 \%$ & $43.10 \%$ & $48.90 \%$ & $0.00 \%$ \\
\hline & 2009 & $6.90 \%$ & $13.00 \%$ & $41.30 \%$ & $38.90 \%$ \\
\hline & 2014 & $2.97 \%$ & $4.82 \%$ & $16.23 \%$ & $75.97 \%$ \\
\hline \multirow{3}{*}{$\begin{array}{l}326 \text { Industria del plástico y del } \\
\text { hule. }\end{array}$} & 2004 & $0.70 \%$ & $5.20 \%$ & $31.90 \%$ & $62.30 \%$ \\
\hline & 2009 & $0.60 \%$ & $5.10 \%$ & $28.80 \%$ & $65.50 \%$ \\
\hline & 2014 & $0.63 \%$ & $6.23 \%$ & $25.31 \%$ & $67.84 \%$ \\
\hline \multirow{4}{*}{$\begin{array}{l}327 \text { Fabricación de productos a } \\
\text { base de minerales no metálicos. }\end{array}$} & 2004 & $12.30 \%$ & $19.90 \%$ & $30.90 \%$ & $37.00 \%$ \\
\hline & 2009 & $13.10 \%$ & $11.50 \%$ & $32.40 \%$ & $43.10 \%$ \\
\hline & 2014 & $10.64 \%$ & $14.17 \%$ & $19.51 \%$ & $55.68 \%$ \\
\hline & & & & & Continúa \\
\hline
\end{tabular}




\begin{tabular}{|c|c|c|c|c|c|}
\hline & & & & \multicolumn{2}{|c|}{ Contimúa de página anterios } \\
\hline \multirow{3}{*}{331 Industrias metálicas básicas. } & 2004 & $4.00 \%$ & $14.50 \%$ & $36.40 \%$ & $45.10 \%$ \\
\hline & 2009 & $2.80 \%$ & $8.40 \%$ & $10.40 \%$ & $78.50 \%$ \\
\hline & 2014 & $1.90 \%$ & $7.01 \%$ & $22.55 \%$ & $68.53 \%$ \\
\hline \multirow{3}{*}{$\begin{array}{l}332 \text { Fabricación de productos } \\
\text { metálicos. }\end{array}$} & 2004 & $8.10 \%$ & $6.30 \%$ & $22.50 \%$ & $63.00 \%$ \\
\hline & 2009 & $9.20 \%$ & $5.40 \%$ & $14.60 \%$ & $70.80 \%$ \\
\hline & 2014 & $8.84 \%$ & $6.13 \%$ & $16.47 \%$ & $68.55 \%$ \\
\hline \multirow{3}{*}{$\begin{array}{l}333 \text { Fabricación de maquinaria y } \\
\text { equipo. }\end{array}$} & 2004 & $2.90 \%$ & $6.60 \%$ & $21.40 \%$ & $69.00 \%$ \\
\hline & 2009 & $0.80 \%$ & $6.60 \%$ & $47.80 \%$ & $44.70 \%$ \\
\hline & 2014 & $1.30 \%$ & $3.78 \%$ & $15.46 \%$ & $79.45 \%$ \\
\hline \multirow{3}{*}{$\begin{array}{l}334 \text { Fabricación de equipo de } \\
\text { computación, comunicación, } \\
\text { medición y de otros equipos, } \\
\text { componentes y accesorios } \\
\text { electrónicos. }\end{array}$} & 2004 & $0.10 \%$ & $0.90 \%$ & $12.90 \%$ & $86.20 \%$ \\
\hline & 2009 & $0.10 \%$ & $0.40 \%$ & $7.50 \%$ & $92.10 \%$ \\
\hline & 2014 & $0.08 \%$ & $1.07 \%$ & $11.04 \%$ & $87.81 \%$ \\
\hline \multirow{3}{*}{$\begin{array}{l}335 \text { Fabricación de accesorios, } \\
\text { aparatos eléctricos y equipo de } \\
\text { generación de energía eléctrica. }\end{array}$} & 2004 & $0.50 \%$ & $3.00 \%$ & $18.80 \%$ & $77.70 \%$ \\
\hline & 2009 & $0.50 \%$ & $1.70 \%$ & $8.10 \%$ & $89.80 \%$ \\
\hline & 2014 & $0.43 \%$ & $3.94 \%$ & $15.96 \%$ & $79.68 \%$ \\
\hline \multirow{3}{*}{$\begin{array}{l}336 \text { Fabricación de equipo de } \\
\text { transporte. }\end{array}$} & 2004 & $0.20 \%$ & $1.20 \%$ & $7.60 \%$ & $91.00 \%$ \\
\hline & 2009 & $0.80 \%$ & $1.70 \%$ & $9.30 \%$ & $88.10 \%$ \\
\hline & 2014 & $0.33 \%$ & $1.55 \%$ & $9.99 \%$ & $88.14 \%$ \\
\hline \multirow{3}{*}{$\begin{array}{l}337 \text { Fabricación de muebles, } \\
\text { colchones y persianas. }\end{array}$} & 2004 & $4.40 \%$ & $10.30 \%$ & $28.20 \%$ & $57.20 \%$ \\
\hline & 2009 & $9.70 \%$ & $5.60 \%$ & $18.70 \%$ & $66.00 \%$ \\
\hline & 2014 & $8.07 \%$ & $7.19 \%$ & $18.91 \%$ & $65.82 \%$ \\
\hline \multirow{3}{*}{$\begin{array}{l}339 \text { Otras industrias } \\
\text { manufactureras. }\end{array}$} & 2004 & $1.00 \%$ & $2.40 \%$ & $13.60 \%$ & $83.10 \%$ \\
\hline & 2009 & $1.30 \%$ & $1.40 \%$ & $6.80 \%$ & $90.50 \%$ \\
\hline & 2014 & $1.36 \%$ & $1.64 \%$ & $10.68 \%$ & $86.32 \%$ \\
\hline \multirow{3}{*}{ Total sector industrial } & 2004 & $4.60 \%$ & $5.10 \%$ & $19.40 \%$ & $71.00 \%$ \\
\hline & 2009 & $5.80 \%$ & $4.10 \%$ & $14.90 \%$ & $75.20 \%$ \\
\hline & 2014 & $5.32 \%$ & $4.89 \%$ & $16.42 \%$ & $73.37 \%$ \\
\hline
\end{tabular}

Fuente: Elaboración propia con datos de INEGI, Censos Económicos 2004, 2009 y 2014. 


\subsection{Interpretaciones y discusión a la luz de algunas perspectivas teóricas.}

En este apartado se busca explicar los cambios en la Manufactura en Baja California y la estructura del empleo por estrato empresarial resultante, a la luz de distintas perspectivas teóricas. En general, los resultados del trabajo indican una pérdida de participación en el empleo de las Pequeñas y Medianas Empresas en la manufactura desde los noventa; y una ampliación de la participación de la gran empresa, mientras que la participación del estrato de microempresas, ha permanecido relativamente estable desde los noventa, aunque se aprecia una ampliación de su participación a partir del 2000.Ello sugiere que en épocas de expansión económica de EEUU y BC, como en la década de los 90, la participación de las pequeñas y medianas empresas dentro de la economía solía ser mayor; a partir de la desaceleración económica de 2000 y en particular de 2003, esta participación se redujo considerablemente, concentrándose el empleo en la gran empresa en la mayoría de las industrias.

De igual forma, se encuentra que las MiPyMEs presentan una participación relativamente alta en sectores tradicionales de baja sofisticación tecnológica, requerimientos de capital bajos y de escala reducida, como las industrias alimentarias y de bebidas; mientras que las pequeñas, en menor medida, y en particular las medianas empresas, poseen una participación relativamente alta en sectores de sofisticación tecnológica intermedia y mayores requerimientos de capital y escala, tales como las Industrias de la madera, y textiles, y antes, en las industrias del papel, minerales no metálicos, y las industrias metálicas básicas. Por su parte, la gran empresa presenta una participación relativamente más alta en la mayoría de las industrias; dicha ventaja relativa aumenta a medida que se incrementan la sofisticación tecnológica y los requerimientos de capital de las industrias, tales como la Fabricación de maquinaria y equipo, equipo de transporte, accesorios de computación, comunicación, medición, componentes electrónicos, y las industrias metálicas básicas.

Una primera aproximación para entender la tendencia de largo plazo de la manufactura en $\mathrm{BC}$ se deriva de la economía industrial tradicional, y que tiene que ver con la interacción entre el entorno económico de Estados Unidos que se transmitió a Baja California, y la escala mínima eficiente (MES) características de las industrias. En esta perspectiva se encuentran Weiss (1964) y Weiss (1979), quienes sugieren que las pequeñas empresas no logran alcanzar las MES de las industrias por lo que operan en escalas sub-óptimas o ineficientes, y producen a costos medios por encima de las grandes empresas más eficientes. Ello debe presentarse con mayor razón en la manufactura que le caracterizan MES más altas que en otros sectores como el comercio y los servicios. Otras implicaciones sobre la dinámica industrial las encuentra Bain (1956), al asumir que las funciones de costos medios a largo plazo en las industrias son declinantes y después se aplanan, una vez alcanzando la MES de la industria; entonces a medida que la demanda se expande empiezan a entrar al mercado empresas del tamaño de la MES, lo que reduce la concentración industrial. Ello 
es así, porque un mercado amplio da cabida a más empresas de tamaño de la MES. Una situación inversa ocurre cuando la demanda se contrae, ya que un mercado pequeño acoge a menos empresas del tamaño de la MES, promoviendo así la concentración. Este resultado fue posteriormente refinado por Sutton $(1991,2001)$, en el sentido de que el modelo de concentración industrial era aproximadamente correcto para industrias caracterizadas por costos hundidos exógenos (costos que no pueden ser recuperados por las empresas cuando su producción cesa. Sin embargo, cuando se consideran otras fuerzas que gobiernan la estructura y evolución de las industrias, como el caso de los costos hundidos endógenos determinados por las decisiones estratégicas de la empresa o empresas líderes en un mercado para elevar la demanda (gastos en publicidad, inversiones en investigación y desarrollo, costos asociados con la diferenciación de producto, entre otros); bajo estas circunstancias la expansión de los mercados puede exacerbar la concentración industrial (Robinson y Chiang, 1996; Kwoka y White, 2001).

Ello puede explicar porque en momentos en que la economía crecía favorablemente como en los 90, la expansión del mercado trajo como resultado no solo el incremento de la participación de la gran empresa en Baja California, sino también, el arribo de empresas más pequeñas sub-óptimas productoras de bienes finales o bien proveedores de empresas grandes en subsectores en que presentan ventajas relativas, motivadas por mercados amplios. Ello se materializó, primero, en un aumento del número de empresas maquiladoras de empresas líderes y de sus proveedores que se instalaron alrededor de una economía mundial en crecimiento, y posteriormente, cuando la economía empezó a presentar signos de desaceleración y de paralización a partir de 2003, este proceso precipitó la salida de las empresas maquiladoras de menor tamaño consideradas sub-optimas, como el caso de las pequeñas y medianas empresas que coexistían con empresas grandes. Esta dinámica ha traído como resultado un proceso de concentración industrial en la manufactura en BC.

Otra explicación sobre la evolución de la industria manufacturera hacia la concentración industrial en las grandes, se deriva de la nueva economía industrial, que sugiere que dicha concentración puede ser producto de las características tecnológicas de los sectores y empresas que integran la industria. Según Audretsch (2001, pp.37-51), el hecho de que las empresas sean sub-óptimas o que presenten una escala pequeña, no inhibe necesariamente su entrada al mercado o precipita el cierre de la empresa frente a competidores grandes considerados óptimos en su escala. Estas empresas también están en condiciones de sobrevivir en el mercado e incluso crecer, pero ello está condicionado por factores técnicos como los niveles de capital utilizados característicos de las industrias, aspectos dinámicos de la entrada, sobrevivencia, crecimiento y cierre propios de los emprendimientos y de la evolución de las industrias; el nivel tecnológico, los tamaños de mercado, y las probabilidades de innovación en la industria. Hoy en día, muchos sectores tecnológicos de vanguardia presentan tamaños de escala apropiados para las pequeñas empresas donde los niveles 
de capital son bajos y los bienes que venden son de alto valor agregado e intensivos en capital humano. Estas circunstancias tenderían a favorecer no solo la expansión de dichas empresas sino también ampliar su participación en la industria en menoscabo de las grandes empresas reduciendo la concentración industrial. Sin embargo, en Baja California, al igual que el resto del país, persisten niveles de desarrollo consistentes con industrias de altas MES donde las grandes empresas pueden ser más eficientes en costos y en productividad y, por tanto, presentan aun ventajas con respecto a las pequeñas. Bajo estas circunstancias, las grandes empresas predominan por su peso en los mercados frente a las pequeñas.

El hecho de que las microempresas prevalezcan con una participación prácticamente constante puede deberse a la reducción de la dinámica de la economía en su conjunto y de algunos sectores manufactureros que han presentado cierre de empresas pequeñas y medianas y cuyos desempleados han emprendido micronegocios, lo que se refleja en una persistencia de estos negocios en el sector (Mungaray et al., 2015). Según Georgellis et al. (2005), este proceso se le denomina teóricamente recession-push o "efecto refugio" que explica la apertura de empresas como una respuesta a las circunstancias difíciles que imperan en la economía y en los mercados laborales, que hacen que los individuos emprendan para crearse su propia oportunidad de ocupación.

\section{$\rightarrow$ 4. Conclusiones.}

Este trabajo se orientó a explicar la economía de $\mathrm{BC}$ y la evolución de la industria manufacturera a través del análisis de los cambios en la estructura del empleo. Ello se ha hecho a partir de algunos planteamientos teóricos y empíricos desde la Economía Industrial tradicional y la nueva Organización Industrial. El trabajo encuentra que las tendencias de concentración de la gran empresa en el empleo manufacturero de $\mathrm{BC}$, y la disminución de la participación de las pequeña y medianas empresas, se debe a una interacción entre el nivel tecnológico característico de las industrias, que siguen favoreciendo la gran empresa, y la reducción de la dinámica económica, que ha promovido la ampliación de la concentración industrial. Por otro lado, el sostenimiento de la participación de la microempresa dentro de la industria en el largo plazo puede deberse al deterioro de la dinámica económica con respecto a los noventa, que ha motivado el emprendedurismo de personas desempleadas.

Este trabajo da pistas para pensar que el proceso de reestructuración industrial de $\mathrm{BC}$, que ha significado un deterioro de la participación de la pequeña y la mediana empresa, una ampliación de la gran empresa y una persistencia e incluso incremento de la participación de la microempresa es, en parte, consecuencia de cambios que se han venido dando a nivel mundial desde 2001, que 
han reducido la dinámica industrial en Estados Unidos, y que ha tenido repercusiones en el Estado. Es posible que dichos cambios, que al final se materializaron con la crisis de 2008, estén siendo impulsados por cambios tecnológicos que favorecen la pequeña empresa en EEUU, que no están siendo asimilados en BC o están siendo asimilados muy lentamente, y han significado la reorientación de empresas tecnológicas de capital extranjero a otras regiones; la desaparición de nichos de oportunidad para emprendedores locales e incluso extranjeros en el Estado, y el establecimiento de actividades industriales que requieren escalas amplias de producción. Por ello, es importante acelerar el proceso de construcción de una economía más orientada al conocimiento y a la innovación, que permitan fortalecer el nivel de los emprendimientos y el tejido industrial, y el consecuentemente, la estructuración de un sector de pequeñas empresas más sofisticado y con potencial de crecimiento que aproveche los mercados domésticos e internacionales o bien puedan encadenarse las empresas de mayor tamaño orientadas a los mercados globales. Deigual forma, es necesario generar mecanismos compensatorios a través de programas encaminados a apoyar el emprendimiento de los micronegocios, que si bien son menos sofisticados, son importantes generadores de oportunidades laborales.Los sistemas regionales de innovación integrados por diversos actores juegan un papel importante: la educación, la investigación científica y su difusión, los procesos de innovación, la formación empresarial, y la organización institucional para el emprendimiento. 


\section{Bibliografía y referencias documentales}

Audretsch, David (2001). "Research issues relating to structure, competition and performance of small technology-based firms" en Small Business Economics, 16, pp.37-51.

Bain, Joe Staten (1956). "Barriers to new competition: their character and consequences in manufacturing industries" en Harvard University Press, vol. 3, pp. 329.

Georgellis, Yannis, John Grant, et al (2005), "Self-employment longitudinal dynamics: a review of the literature" en Economic Issues, vol.10, núm. 2, pp.51-84.

Instituto Nacional de Estadística, Geografía e Informática, Censo económico de 1989. http://www.inegi.org. $\mathrm{mx} /$ est/contenidos/Proyectos/ce/Default.aspx

, Censo económico de 1994. http://www.inegi.org.mx/est/contenidos/Proyectos/ce/Default.aspx

, Censo económico de 1999. http://www.inegi.org.mx/est/contenidos/Proyectos/ce/Default.aspx

, Censo económico de 2004. http://www.inegi.org.mx/est/contenidos/Proyectos/ce/Default.aspx

, Censo económico de 2009. http://www.inegi.org.mx/est/contenidos/Proyectos/ce/Default.aspx

, Censo económico de 2014. http://www.inegi.org.mx/est/contenidos/proyectos/ce/ce2014

, (2010). Tablas comparativas SCIAN MÉXICO 2002-CMAP 1994. P.P. 167.http://www.inegi.org.mx/ sistemas/scian/contenidos/Tablas\%20comparativas/Tabla\%20Comparativa\%20VI.pdf.

Kwoka Jr., Johnand White, et al (2001). "The new industrial organization and small business" en Small Business Economics, 16, pp.12-30.

Mungaray Alejandro, Antonio Escamilla, et al (2014). "Crisis, migración y estructura del empleo en Baja California" en Políticas públicas para el desarrollo microempresarial en Baja California, Alejandro Mungaray, Natanael Ramirez, et al, UABC, pp. 89-107.

Mungaray Alejandro (2015) "Emprendimiento de micro y pequeñas empresas mexicanas en un escenario local de crisis económica: el caso de Baja California, 2008-2011” en Frontera Norte, vol. 27, núm. 53, enero-junio, pp.115-146.

Robinson, William y Chiang Jeongwen (1996). "Are Sutton's predictions robust?: Empirical insights into advertising, R \& D, and concentration" en The Journal of Industrial Economics, pp.389-408.

Sutton, John (1991). "Sunk costs and market structure: price competition, advertising, and the evolution of concentration" en MIT Press, pp.502-520.

Sutton, John (2001). Technology and market structure: theory and history en MIT Press.

Weiss, Leonard (1964). "The survival technique and the extent of suboptimal capacity" en The Journal of Political Economy, pp. 246-261.

Weiss, Leonard (1979) “The structure-performance paradigm and antitrust" en University of Pennsylvania Law Review, 127, pp.1104-1140. 
Números anteriores:

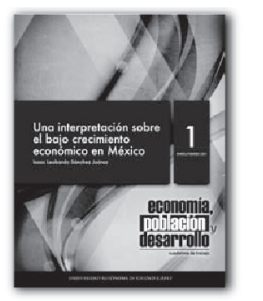

Economía, población y desarrollo.
Cuadernos de trabajo №1

Enero-Febrero 2011
Una interpretación sobre el bajo

crecimiento economico en México
Isaac Leobardo Sánchez Juárez

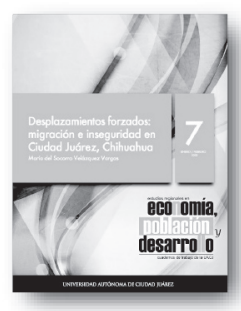

Economia, población y desarroll

Cuadernos de trabajo $\mathrm{N}$ -
Encro-Fcbrcro 2012

Desplazamientos forzados
migración e inseguridad

Ciudad Juárez, Chihuahua
Maria del Socorro Velázquez Varga

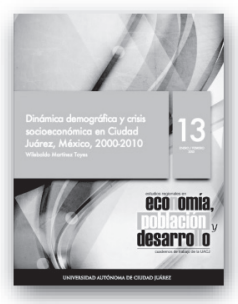

Economiá, población y desarrollo

de trabajo $N$

Dinámica demográ́fica y crisis
socieconómica en Ciudad Juáre Mexico, 2000-2010

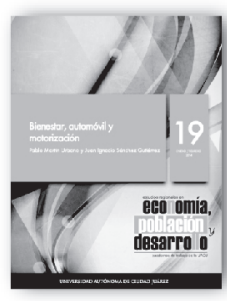

Economía, población y desarroll Enero - Febrero 2014 Bienestar, automóvil y motorización
Pablo Martín Urbano y Miosánchez Gutiérrez

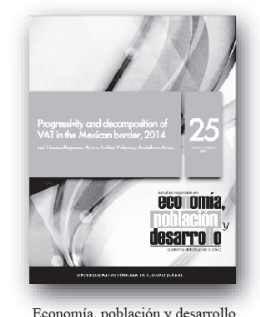

Cuadernos de trabajo No $_{0}$
Conomia,

Encro - Febrero 2015

Progressivity and decomposition of
VAT in the Mexican border, 2014 Abdelkim Araar

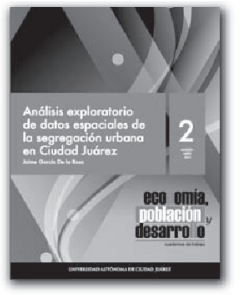

Economía, población y desarrollo.
Cuadernos de trabajo № 2

Marzo-Abril 2011

espaciales de la segregacón

Jaime Garcia De la Rosa

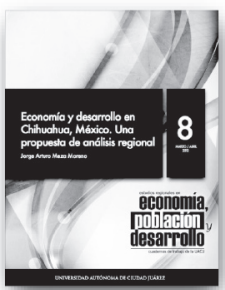

Economia, población y desarrollo

Cuadernos de trabajo №7

Economía y desarrollo en

propuesta de análisis regiona

Jorge Arturo Meza Moreno

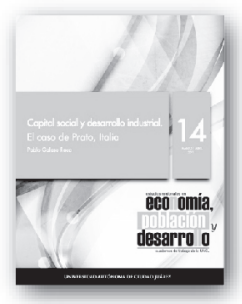

Economía, población y desarrollo

Marzo - Abri1 2013

Capital social y desarrollo

Pablo Galaso Reca

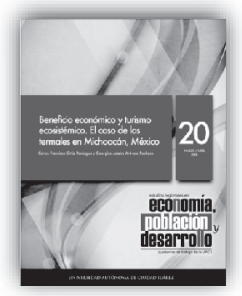

Economia, población y desarrollo

Marzo - Abril 2014

Beneficio económico y turismo

enico. El caso de las ter
en Michoacán, Mésico

arlos Franciseo Ortiz Paniagu

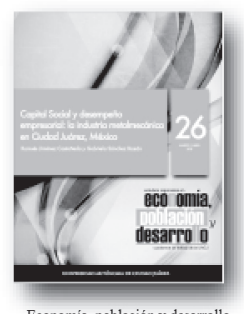

Economía, población y desarrollo

Cuadernos de trabajo № 26
Marzo - Abril 2015

Capital Social y desempeño empresa
la industria metalmecánica en

a industria metalmecánica en
Ciudad Juárez, México

Ramsés Jiménez Castañeda y
Gabriela Sáncez Bazán
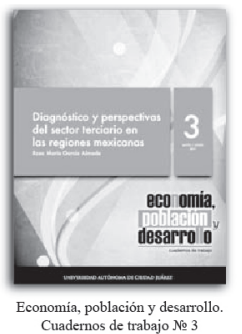

Diagnóstico y perspectivivas

regiones mexicanas
rosa Mária Garcia Almad

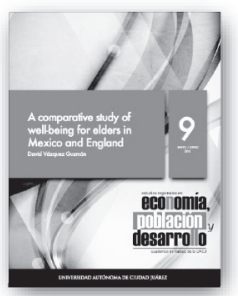

Economia, población y desarrollo

Cuadernos de trabajo № 9
Mayo - Junio 2012

A comparative study of

Mexico and England
David Vázquez Guzmán

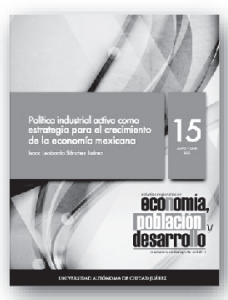

Economia, población y desarroll

Madernos de trabajo
Mayo - Junio 2013

Politica ind ustrial activa como

strategia para el crecimiento

Isaac Lcobardo Ś́nexicana
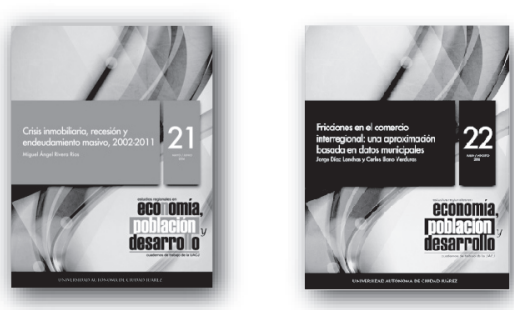

Economia, población y desarrollo

Cuademos de trabajo
Mayo - Junio 2014

Crisis inmobiliaria, recesión y
adeudamiento masivo, $2002-2011$

Miguel Ángel Rivera Rios

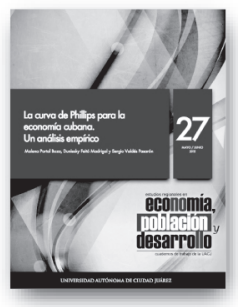

Economia, población y desarrollo

Cuadernos de trabajo № 27

a curva de Phillips para

economía cubana.

Malena Portal Boza, Duniesky Feitó

Economía, población y desarrollo.
Cuadernos de trabsio

julio-Agosto 201

Los indices IDH y FGT en la

mera década del siglo XX

Economía, población y decarrollo

Cuadernos de trabajo №
Julio - Agosto 2012

Political competition and the

edistribution in a federation

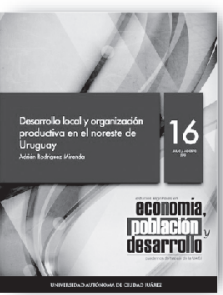

Economía, población y desarrollo

Cuadernos de trabajo №
Julio - Agosto 2013

Desarrollo local y organización
productiva en el noroeste de Urugu

Economía, población y desarrollo

Julio - Agosto 2014

Ficciones en el comercio

basada en datos municipales
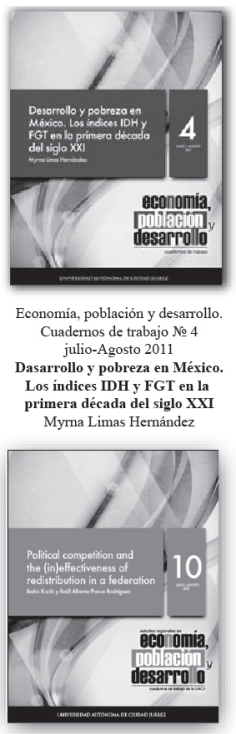

Jorge Diaz Lanchas y Carlos Llano Verduras
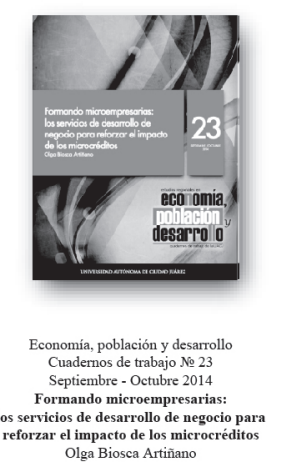

Cuadernos de trabajo № 24

El crecimiento de las regiones

el paradigma del desarrollo

divergente. Un marco térico
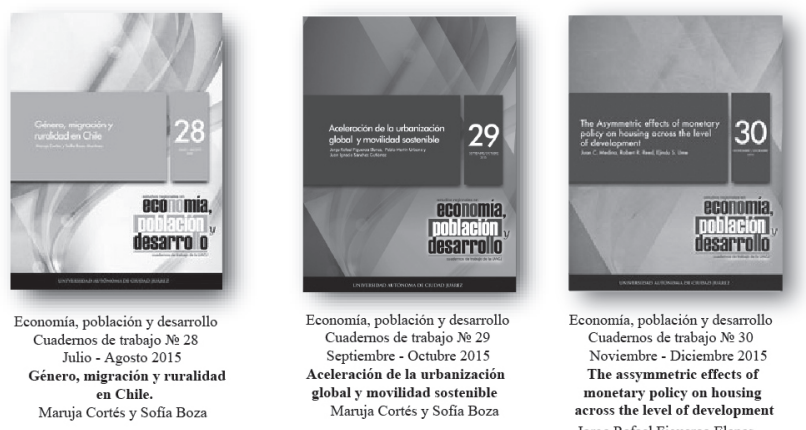

conomía, población y desarrol

Cuadernos de trabajo № 30

The assymmetric effects of

monetary policy on housing

Jorge Rafael Figueroa Elenes,

Juan Ignacio Sánchez Gutiérrez 
Números anteriores:
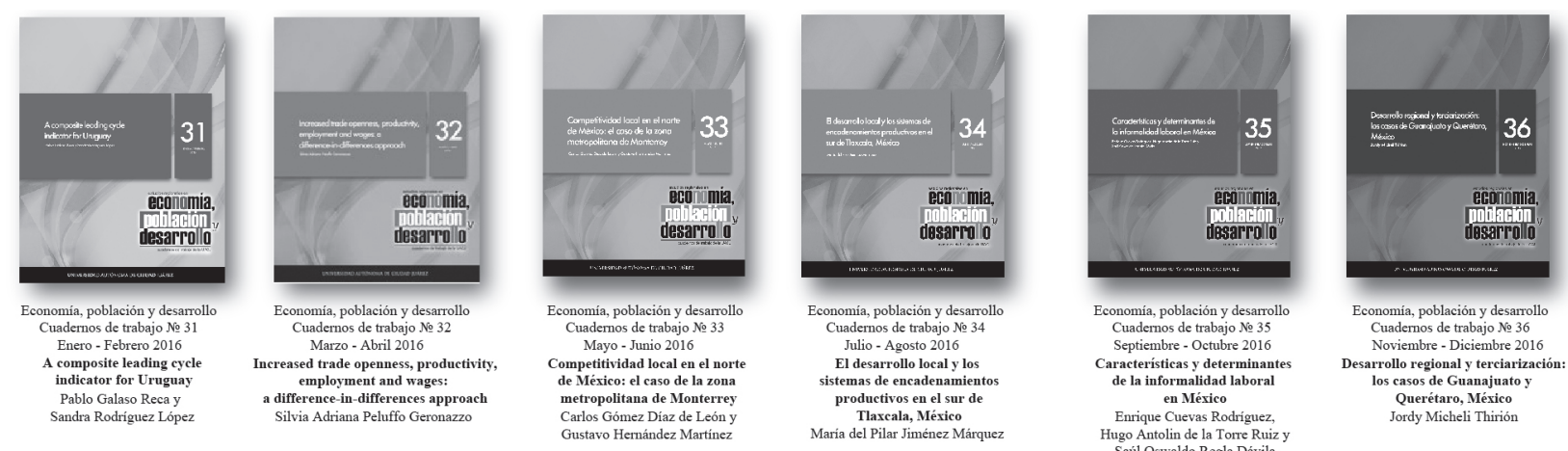

Economía, población y desarrollo Septiembre - Octubre 2016

Caracteristicas $y$ determinantes
de la informalidad laboral en México

Enrique Cucvas Rodrígucz,
Hugo Antolin de lo Torre Ruz

Gustayo Herrández Martinez

Maria del Pilar Jiménez Márquez
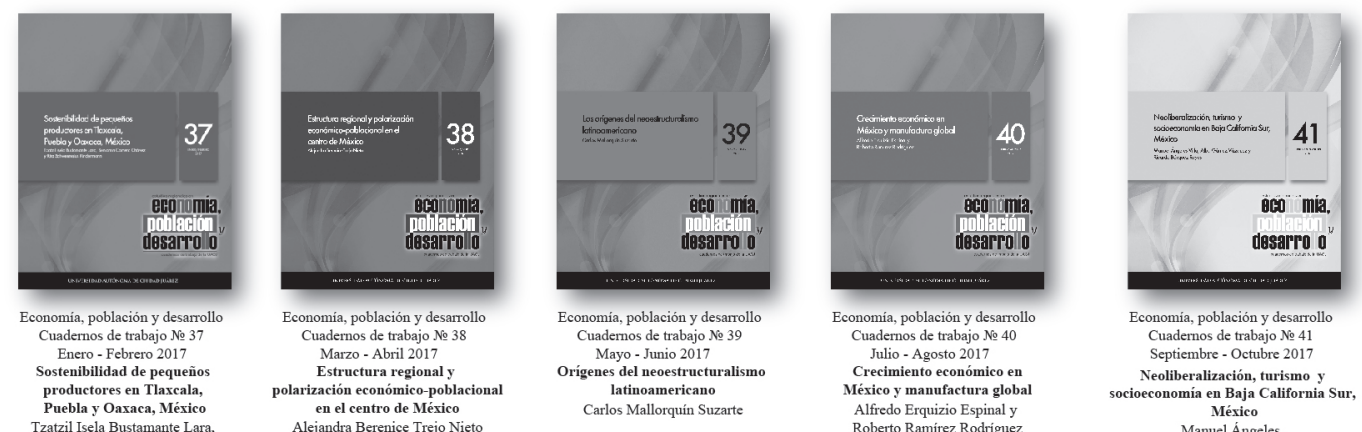

Economia, población y desarrollo Noviembre - Diciembre 2016 Desarrollo regional y terciarización:
los casos de Guanajuato y Querétaro, México

Cuadernos de trabajo № 39 Mayo - Junio 2017

Enero - Febrero 2017 ostenibilidad de pequeños

productores en Tlascala,

zatzil Iscla Bustamante Lara, Benjamin Carrera Chávez y
Rita Schwentesius Rindermanı

Alcjandra Bereniec Trajo Nie

latinoamericano

Economía, población y desarroll
Cuademos de trabajo № 40

Julio - Agosto 2017

Crecimiento economico en
Mésico y manufactura global

Alfredo Erquizio Espinal y

Economía, población y desarrollo

Septiembre - Octubre 2017

Neoliberalización, turismo y
ioeconomía en Baja California

México

Manuel Ángeles,

Ricardo Bórquez

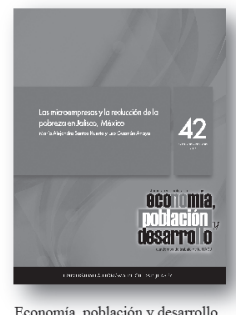

conomía, población y desarrollo Cuadernos de trabajo № 42
Noviembre - Diciembre 2017 Las microempresas y la reducción
de la pobreza en Jalisco, México Maria Alcjandra Santos Hucrta Leo Guzmann Anaya

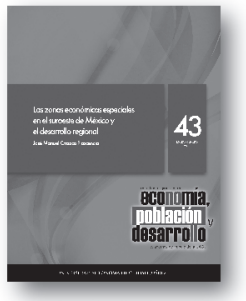

Economia, población y desarrol Cuadernos de trabajo $\mathrm{No}$
Enero - Febrero 2018

Las zonas económicas especiales el desarrollo regional José Manuel Orozco Plascenci

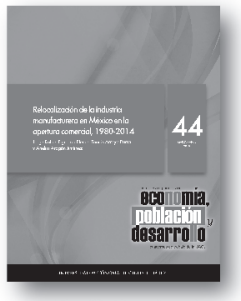

Economia, poblacion y desarrollo Cuadernos de trabajo №
Marzo - Abril 2018

Relocalización de la industria apertura comercial 1980-2014 Jorge Rafael Figueroa Elenes, Tomás Aroyo Parra y
Aneliss Aragón Jiménez

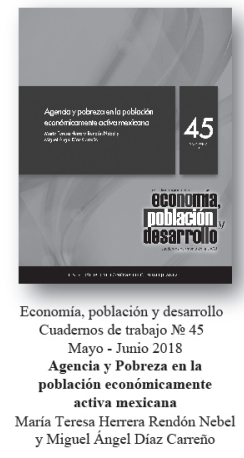




\section{$\rightarrow$ Normas Editoriales}

\section{Para el documento general:}

Tipo de letra: Times New Roman.

Tamaño: 11 puntos.

Interlineado: 1.5 espacios.

Títulos y subtítulos:

El texto principal en 11 puntos. Títulos 12 puntos (en resaltado). Subtítulos 11 puntos. Cada título y subtítulo deberá numerarse bajo el siguiente orden: $1,1.1,2,2.1,2.2 \ldots$

La extensión máxima de los cuadernos de trabajo será de 40 cuartillas.

La primera vez que se emplee una sigla en el texto se especificará primero su equivalencia completa y después la sigla.

\section{Hoja de presentación:}

Título:

14 puntos, centrado, resaltado.

Nombre de autor(es):

12 puntos

Resumen y abstract:

Debe incluir resumen en español y abstract (diez puntos), no mayor a 250 palabras

Palabras clave:

Incluir entre tres y cinco palabras clave, en español e inglés

Referencia del autor o autores:

Institución de adscripción, grado académico y líneas-grupos de investigación que desarrolla y a los que pertenece.

\section{Sistema de referencia de citas:}

Harvard-APA

Las citas bibliográficas en el texto deberán incluir entre paréntesis sólo el apellido del autor, la fecha de publicación y el número de página; por ejemplo: (Quilodrán, 2001: 33).

\section{Notación en sección de bibliografía y fuentes de información:}

Se deberá incluir al final del texto. Toda referencia deberá estar mencionada en el texto o notas de pie de página.

Cada referencia iniciará con el primer apellido o los apellidos, luego el nombre del autor, y después, entre paréntesis, el año de publicación seguido de un punto. Ejemplos:

Se deberá incluir al final del texto. Toda referencia deberá estar mencionada en el texto o notas de pie de página.

Cada referencia iniciará con el primer apellido o los apellidos, luego el nombre del autor, y después, entre paréntesis, el año de publicación seguido de un punto. Ejemplos:

Artículo:

Ros, Jaime (2008). "La desaceleración del crecimiento económico en México desde 1982”, en Trimestre Económico, vol. 75, núm. 299, pp. 537-560.

Libro:

Villarreal, René (2005). Industrialización, competitividad y desequilibrio externo en México. 
Un enfoque macroindustrial y financiero (1929-2010), México, Fondo de Cultura Económica. Capítulo de libro:

Castillo, Manuel Ángel (2003). "La política de inmigración en México: un breve recuento", en Manuel Ángel Castillo, Alfredo Lattes y Jorge Santibáñez (coords.), Migración y fronteras, Tijuana, El Colegio de la Frontera Norte / Asociación Latinoamericana de Sociología / El Colegio de México, pp. 425-451.

\section{Notas de pie de página:}

Se utilizarán para hacer indicaciones complementarias, aclaraciones o ampliación de una explicación. La notas de pie de página en Times New Roman, 10 puntos.

\section{Tipología de imágenes dentro del texto:}

Cuadro

Gráfica

Diagrama

Mapa

Figura

Todas las imágenes deben ser numeradas y mencionadas dentro del texto. A toda imagen debe incluirse la fuente.

Las indicaciones de la imagen: tipo y número de imagen, título de imagen y fuente se escriben en 10 puntos. En el texto poner como imagen los mapas, figuras, gráficas y diagramas -con el ánimo de no perder el formato realizado por el autor.

\section{Ecuaciones y fórmulas:}

Si se utilizan ecuaciones o fórmulas deberá utilizarse el editor de ecuaciones de Word y numerarse.

\section{Envío de trabajos}

Los trabajos deben ser enviados a la dirección de correo: lgtz@uacj.mx. Con el Dr. Luis Enrique Gutierrez Casas, editor de esta publicación.

La aceptación de cada colaboración dependerá de la evaluación de dos dictaminadores especialistas en la materia que se conservarán en el anonimato, al igual que el autor (autores) para efectos de la misma. 


\section{$\rightarrow$ Editorial Guidelines}

\section{For General Document:}

Font type: Times New Roman.

Size: font size 11 .

Paragraph: 1.5 line spacing.

Titles and subtitles: Main text font size 11. Titles font size 12 (Bold). Subtitles font size 11.

Each title and subtitle should be numbered in the following order: 1, 1.1, 2, 2.1, 2.2...

The maximum length of the workbooks will be 40 pages.

The first time an abbreviation is used in the text will be specified first complete equivalence and then stands.

\section{Front cover:}

Title:

Font size 14, centered, Bold.

Author name(s):

Font size 12.

Abstract:

It should include abstract in Spanish and abstract (font size 10), no more than 250 words.

Keywords:

Include three to five keywords, in Spanish and English.

Reference of author:

Institution of affiliation, academic degree and line-developed by research groups and belonging.

\section{Bibliographical appointment system:}

Harvard-APA

Citations in the text should include between parentheses only the author's name, publication date and page number, for example:

(Quilodrán, 2001: 33).

\section{Notation about Bibliography section and Information fonts:}

Should be included at the end of the text. All references must be mentioned in the text or footnotes page.

Each reference starts with the first name or last name, then the name of the author, and then, in parentheses, the year of publication followed by a period. Examples:

Article:

Ros, Jaime (2008). “La desaceleración del crecimiento económico en México desde 1982”, en Trimestre Económico, vol. 75, núm. 299, pp. 537-560.

Book:

Villarreal, René (2005). Industrialización, competitividad y desequilibrio externo en México. Un enfoque macroindustrial y financiero (1929-2010), México, Fondo de Cultura Económica.

Book chapter:

Castillo, Manuel Ángel (2003). "La política de inmigración en México: un breve recuento”, en Manuel Ángel Castillo, Alfredo Lattes y Jorge Santibáñez (coords.), Migración y fronteras, Tijuana, E1 Colegio de la Frontera Norte / Asociación Latinoamericana de Sociología / El Colegio de México, pp. 425-451. 


\section{Footnotes:}

Must be used to make additional indications, clarification or expansion of an explanation. The footnotes must be in Times New Roman, font size 10.

\section{Image typology inside text:}

Picture

Graph

Diagram

Map

Figure

All images must be numbered and mentioned in the text, should include the source image. The indications of the image: type and number of image, image title and source are written in 10 font size. In the text set as image maps, figures, graphs and charts-with the intention of not losing the formatting by the author.

\section{Equations and Formulae:}

When using equations or formulas should be used in Microsoft Word equation editor and numbered.

\section{Paper sending}

Entries must be sent to the email address: lgtz@uacj.mx. With Dr. Luis Enrique Gutiérrez Casas, editor of this publication.

Acceptance of each collaboration will depend on the evaluation of two examiners skilled in the art to be kept anonymous, like the author(s) for the same purposes. 


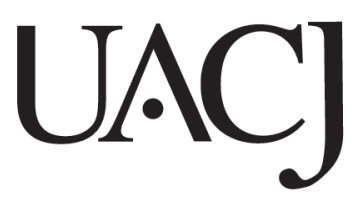

Esta obra se terminó de imprimir en junio de 2018 Cd. Juárez, Chihuahua, México.

Tiraje: 120 ejemplares 
Cuadernos de Trabajo de la Universidad Autónoma de Ciudad Juárez, número 46, julio - agosto de 2018

\section{Director y editor}

Dr. Luis Enrique Gutiérrez Casas

\section{Comité editorial}

Sección internacional

Dra. Sofía Boza Martínez (Universidad de Chile, Chile)

Dra. Olga Biosca Artiñano (Glasgow Caledonian University, Reino Unido)

Dra. Ángeles Sánchez Díez (Universidad Autónoma de Madrid, España)

Dr. Thomas Fullerton Mankin (University of Texas at El Paso, Estados Unidos)

Dr. Adrián Rodríguez Miranda (Universidad de la República, Uruguay)

\section{Sección local}

(Universidad Autónoma de Ciudad Juárez)

Dra. Myrna Limas Hernández

Dra. Ikuho Kochi

Dr. Raúl Alberto Ponce Rodríguez

Dr. Isaac Leobardo Sánchez Juárez

Dr. Héctor Alonso Barajas Bustillos 